\title{
Evaluation of a Residency Peer-to-Peer Intervention in Opioid Prescribing
}

Leora Aquino, MD; Anne Ottney, PharmD, BCPS; Amy Odom, DO; Julie Phillips, MD, MPH

BACKGROUND AND OBJECTIVES: Family physicians play a crucial role in addressing the opioid epidemic. We studied a novel peer-review opioid prescribing educational intervention for family medicine residents that incorporates guided instruction from an interdisciplinary care team.

METHODS: We used a mixed-methods study design in the setting of a family medicine residency program in the Midwestern United States. Residents participated in small group, peer-to-peer discussions of patients chronically prescribed opioids with guidance and input from faculty, a pharmacist, and pharmacy students. Discussions followed a structured approach to evaluation based on guidelines, and written recommendations were given to the patients' resident primary care physician (PCP). For each patient, we reviewed electronic medical records to assess whether PCPs implemented the written recommendations. We used one-way analyses of variance to determine the statistical significance of changes made. The principal investigator interviewed seven participating residents to survey their satisfaction with the curriculum and collated suggestions for improvement.

RESULTS: Over a 3-year period, we reviewed 59 patients as part of the intervention; of these, 53 had complete records reviewed for this study. Patients' morphine milligram equivalent dosage (MME) declined modestly $(P=.035)$. The number and proportion of recommendations implemented was correlated with the decline in $\mathrm{MME}(P=.004$ and $P=.013$, respectively). Interviewed residents unanimously evaluated the curriculum positively, citing that the structured approach helped align their practices with guidelines.

CONCLUSIONS: The guided peer-review intervention effectively decreased chronic opioid use among patients, and residents positively evaluated the curriculum.

(Fam Med. 2022;54(3):221-5.)

doi: 10.22454/FamMed.2022.864395

A ccording to the US Department of Health and Human Services, opioid overdoses accounted for more than 42,000 deaths in $2016,40 \%$ of which were due to prescription opioids. ${ }^{1}$ Through increased isolation, disruption of care, practices of primary care clinicians often do not align with Centers for Disease Control Opioid (CDC) Prescribing Guidelines. ${ }^{5,6}$ One family medicine residency program has demonstrated that an educational intervention utilizing guided instruction can be effective in improving residents' guideline adherence. ${ }^{7,8}$ Other interventions have been studied in the past, but none have explored the qualitative and quantitative value of an interdisciplinary peer-review intervention in a residency program context. ${ }^{9-11}$

We developed a peer-review opioid prescribing educational intervention in a family medicine residency program, incorporating guided instruction, and examined its impact on chronic opioid prescribing practices.

\section{Methods}

The educational intervention was developed in a community-based, university-affiliated suburban family medicine residency program in the Midwest United States. Residents participated in small group, peer-to-peer discussions of patients

From Michigan State University College of Human Medicine, East Lansing, MI (Dr Aquino); Ferris State University College of Pharmacy, Big Rapids, MI (Dr Ottney); and Sparrow-Michigan State University Family Medicine Residency Program, Michigan State University College of Human Medicine (Drs Ottney and Odom) Department of Family Medicine, Michigan State University College of Human Medicine (Dr Phillips). 
being prescribed opioids, with faculty guidance, using a structured approach to evaluation. Patients were selected for discussion based primarily on high average monthly morphine milligram equivalent (MME) dosages over a sustained time period,* but could also be referred for review by their primary care physician (PCP) or another physician. During a typical session, two or three residents, two or three pharmacy students, a physician faculty member, and a pharmacist faculty member reviewed several patients, with one resident leading discussion of each patient. Some sessions also included a social work student and/ or medical student. Residents summarized their recommendations in writing using a structured template based on CDC opioid guidelines. ${ }^{12}$ Each resident participated in one to three sessions over the course of their residency training. Written recommendations were given to each patient's PCP, typically a resident. The PCP resident was never the direct reviewer of their own patients and did not write recommendations for their own patients.

We retrospectively reviewed the written peer-review recommendations and electronic medical records (EMR) of all patients reviewed during a 3-year period (2016-2019). We then coded recommendations into categories: pharmacy, screening, documentation, follow-up, consults/additional diagnostic testing (Table 1). We evaluated each recommendation to determine whether it was followed by the PCP based on data in the EMR. Within each category, we calculated a ratio of recommendations followed to recommendations made. We used one-way analysis of variance (ANOVA) to compare the ratios across categories. We calculated the MME dosage for each patient, just before the intervention and 6 months after. We calculated change in MME using one-way ANOVA.

We recruited residents involved in recent sessions to participate in oneon-one, in-depth interviews using a semistructured approach. The purpose of the interviews was to assess residents' satisfaction and self-reported learning from the peer-review process, in both reviewer and PCP role; identify barriers to implementation of recommendations; and identify areas for improvement. We invited residents to interview with several email solicitations, and all those who responded were interviewed. Interviews were conducted either in-person or by videoconference. The principal investigator (L.A.), a neutral interviewer, recorded, transcribed, and coded each interview in

Table 1: Recommendation Categories and Examples From an Opioid Peer-Review Process

\begin{tabular}{|c|c|}
\hline $\begin{array}{l}\text { Recommendation } \\
\text { Categories }\end{array}$ & Examples \\
\hline \multirow{5}{*}{ Pharmacy } & Recommendations for: \\
\hline & Alternate opioid regimen or taper \\
\hline & Providing naloxone and education on when and how to use naloxone \\
\hline & Decrease or eliminate use of benzodiazepines \\
\hline & Additional medication suggestions or replacements \\
\hline \multirow{3}{*}{ Screening } & Recommendations for: \\
\hline & More frequent or up to date urine drug screens \\
\hline & Visits every 3 months to discuss chronic pain \\
\hline \multirow{3}{*}{$\begin{array}{l}\text { Consults/additional } \\
\text { diagnostic tests }\end{array}$} & Recommendations for: \\
\hline & $\begin{array}{l}\text { Additional consults, alternative treatments, or therapies such as: } \\
\text { physical therapy, neurology, osteopathic manipulative treatment, acupuncture, exercise } \\
\text { programs, psychiatry, cognitive behavioral therapy, headache clinic, and/or other specialists }\end{array}$ \\
\hline & Diagnostic testing such as X-ray of the back, MRI of the spine \\
\hline \multirow{5}{*}{ Documentation } & Recommendations for: \\
\hline & Discussion and documentation of functional care goals \\
\hline & $\begin{array}{l}\text { Updating the problem list to include chronic pain or chronic continuous use of opioids as a } \\
\text { diagnosis }\end{array}$ \\
\hline & Update problem list to reflect current diagnosis and plan \\
\hline & Up-to-date substance use agreement forms \\
\hline \multirow{3}{*}{ Follow-up } & Recommendations for: \\
\hline & Screening and treating for depression (PHQ-9) \\
\hline & Screening and treating sleep apnea \\
\hline
\end{tabular}


detail, using a conventional content analysis approach. ${ }^{13}$ The investigator was supervised by a senior researcher with qualitative research experience (J.P.). This study was approved by the institutional review boards of Michigan State University and Sparrow Clinical Research Institute.

\section{Results}

We reviewed care of 53 patients; an additional five patients were excluded due to incomplete data in the data analysis tool. Patients were most likely to be female, middle-aged, and White, non-Hispanic (Table 2).

Across all patients, a total of 514 recommendations were made (average 10 recommendations per patient). Physicians were more likely to adhere to documentation recommendations than to screening, pharmacy, and consult/additional diagnostic testing recommendations $(P<.05$; Figure 1). We were encouraged to see that the overall, average MME decreased modestly, from 147.75 $(\mathrm{SD}=243.93)$ to $133.05(\mathrm{SD}=235.95)$; $P=.035$. Both the total number of recommendations followed and the proportion of recommendations followed were correlated with a decrease in MME $(P=.004$ and $P=.013$, respectively).

Of 32 eligible residents, seven participated in interviews. Prior to the interactive peer-to-peer exercise, residents primarily received education on opioid management in traditional lecture-based format. Residents reported that peer-review sessions attuned them to safer opioid prescribing practices: incorporating periodic pain contracts, ordering urine drug screens, investigating alternative therapies, conducting a comprehensive review of the patient's problem list and history, and following documentation protocols. They reported better awareness of CDC guidelines and appreciated the systematic approach (Table 3). Residents particularly noted that the pharmacist and pharmacy students enhanced learning by suggesting specific dosages or medication substitutes.

Residents found the recommendations useful when applied to their own patients, prompting them to initiate decreasing opiate dosages and recommending alternative therapies. Several residents incorporated naloxone prescribing into their practice because of the peer-review intervention. However, they also experienced barriers to implementation, including patient resistance to decreasing doses. Some residents had discomfort initiating discussions about tapering with patients who had been on opioids for decades.

Figure 1: Total Recommendations Followed in Proportion to Total Recommendations Made in Each Category

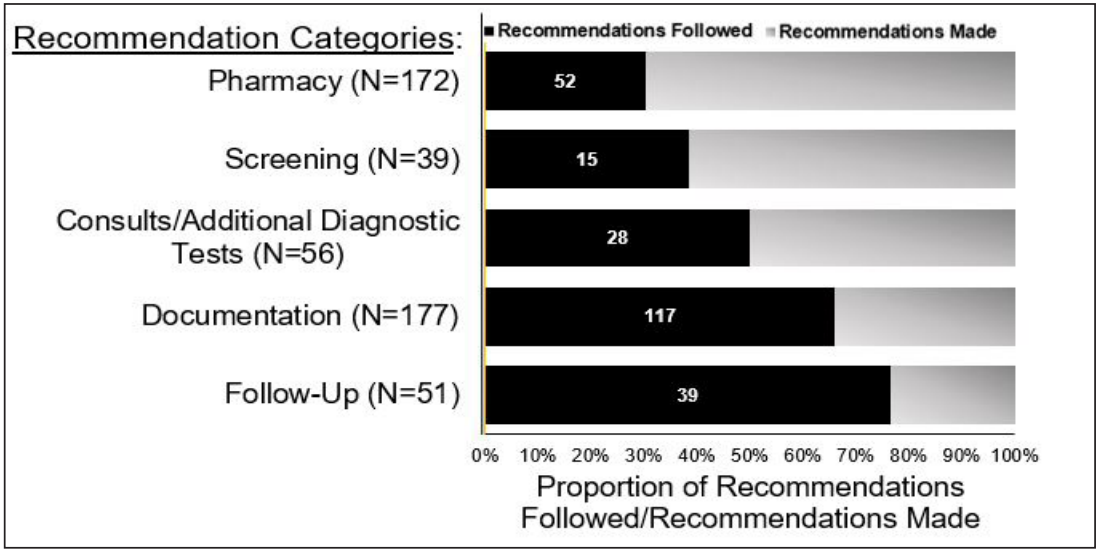

Table 2: Characteristics of Patients Reviewed ( $\mathrm{N}=53$ )

\begin{tabular}{|c|c|}
\hline Characteristic & Patients, $\mathbf{n}(\%)$ \\
\hline \multicolumn{2}{|l|}{ Age, Years } \\
\hline$\leq 44$ & 7 (13) \\
\hline $45-57$ & $19(36)$ \\
\hline $58-70$ & $18(34)$ \\
\hline $71-83$ & $7(13)$ \\
\hline$\geq 84$ & $2(4)$ \\
\hline \multicolumn{2}{|l|}{ Race } \\
\hline White, Non-Hispanic & $38(72)$ \\
\hline Black, Non-Hispanic & $5(9)$ \\
\hline Unknown & $3(6)$ \\
\hline Asian & $1(2)$ \\
\hline \multicolumn{2}{|l|}{ Gender } \\
\hline Female & $36(68)$ \\
\hline Male & $17(32)$ \\
\hline
\end{tabular}

Residents recommended suggestions for improving the peer-review process, including encouraging PCPs to select patients for review, provihensive data about their patient panels, more frequent peer review, and more time for implementation of peer review. One resident stated participating in a second session would increase their understanding of CDC opioid guidelines.

All seven residents interviewed reported that the peer-review process was an effective use of time and indicated a desire to continue the curriculum. One resident noted that the intervention template could be sion of the PCP with more compre- 
Table 3: Resident Impressions and Lessons Learned From the Opioid Peer Review Process

\begin{tabular}{|c|c|c|c|}
\hline Theme & Subtheme & Description & Representative Quotes \\
\hline \multirow{3}{*}{$\begin{array}{l}\text { Impact on } \\
\text { Learning }\end{array}$} & $\begin{array}{l}\text { Systematic } \\
\text { approach }\end{array}$ & $\begin{array}{l}\text { Residents found the } \\
\text { systematic approach } \\
\text { and thorough review } \\
\text { constructive. }\end{array}$ & $\begin{array}{l}\text { "... lo lot of us had [an] opportunity to help a patient with } \\
\text { their chronic pain management in a thorough systematic } \\
\text { way..." "It's helpful to have someone reviewing....They can } \\
\text { find things that you may have missed in a busy clinic day." } \\
\text { (Resident 6) }\end{array}$ \\
\hline & $\begin{array}{l}\text { Heightened } \\
\text { awareness in } \\
\text { prescribing } \\
\text { practices }\end{array}$ & $\begin{array}{l}\text { Residents noted being } \\
\text { more mindful of safe } \\
\text { opioid prescribing } \\
\text { practices. }\end{array}$ & $\begin{array}{l}\text { "Being...more aware of what patients are taking, how often } \\
\text { they're taking it...their diagnosis associated with it... and to } \\
\text { make sure they have naloxone." (Resident 2) }\end{array}$ \\
\hline & $\begin{array}{l}\text { CDC opioid } \\
\text { guidelines }\end{array}$ & $\begin{array}{l}\text { The intervention was } \\
\text { conducive to applying } \\
\text { CDC opioid guidelines. }\end{array}$ & $\begin{array}{l}\text { "It allowed us to evaluate our practice to make sure that } \\
\text { we're being consistent with regulations and guidelines..." } \\
\text { (Resident 6) }\end{array}$ \\
\hline \multirow{5}{*}{ Patient Care } & $\begin{array}{l}\text { Weaning patients } \\
\text { from opioids }\end{array}$ & $\begin{array}{l}\text { Residents noted being } \\
\text { more intentional about } \\
\text { tapering chronic pain } \\
\text { patients off opioids. }\end{array}$ & $\begin{array}{l}\text { "I look at their pain contract, how long they've been on } \\
\text { opioids, have we ever tried to wean, or is there a process of } \\
\text { weaning, or discussing weaning... discussing other options for } \\
\text { pain as well." (Resident 5) }\end{array}$ \\
\hline & $\begin{array}{l}\text { Alternative pain } \\
\text { modalities }\end{array}$ & $\begin{array}{l}\text { The worksheet } \\
\text { prompted residents } \\
\text { to incorporate } \\
\text { alternatives to opioids. }\end{array}$ & $\begin{array}{l}\text { "Just because the patient[s] are on opioids for years, there } \\
\text { is still the possibility for other options to manage pain... and } \\
\text { the worksheet is really helpful...it gives us a lot of options." } \\
\text { (Resident 3) }\end{array}$ \\
\hline & \multirow{3}{*}{$\begin{array}{l}\text { Patient care } \\
\text { barriers }\end{array}$} & $\begin{array}{l}\text { Patients may not be } \\
\text { open to alternative } \\
\text { modalities of pain } \\
\text { management. }\end{array}$ & $\begin{array}{l}\text { "There was one recommendation...acupuncture...but the } \\
\text { patient...wasn't open to it." (Resident } 6 \text { ) }\end{array}$ \\
\hline & & $\begin{array}{l}\text { Residents may } \\
\text { be uncomfortable } \\
\text { weaning patients that } \\
\text { have been on an opioid } \\
\text { for years. }\end{array}$ & $\begin{array}{l}\text { "If [the reviewer] recommended a taper...I didn't do that } \\
\text { because [the patients] have been on it for } 35-40 \text { years... [and] } \\
\text { because it didn't work well for them." (Resident } 2 \text { ) }\end{array}$ \\
\hline & & $\begin{array}{l}\text { Patients on long-term } \\
\text { opioid prescriptions } \\
\text { may be resistant to } \\
\text { weaning. }\end{array}$ & $\begin{array}{l}\text { "I mean some patients are 'difficult'...they’ve been on pain } \\
\text { meds for...years so it's hard to...tell em'...to get off it now... } \\
\text { especially the older ones." (Resident } 5 \text { ) }\end{array}$ \\
\hline \multirow{4}{*}{$\begin{array}{l}\text { Suggestions } \\
\text { for } \\
\text { Improvement }\end{array}$} & PCP engagement & $\begin{array}{l}\text { Ask the PCP which } \\
\text { chronic pain patient } \\
\text { they would like } \\
\text { recommendations for. }\end{array}$ & $\begin{array}{l}\text { "Really get the PCP involved in the...process...because I will } \\
\text { be more likely to pay attention to the opioid review...if you're } \\
\text { giving me feedback on a patient, I don't really know what to } \\
\text { do with." (Resident } 3 \text { ) }\end{array}$ \\
\hline & Regular frequency & $\begin{array}{l}\text { Increase the frequency } \\
\text { of the peer review. }\end{array}$ & $\begin{array}{l}\text { "I mean in a perfect world; we would do it...more } \\
\text { frequent[ly]." (Resident } 4 \text { ) }\end{array}$ \\
\hline & Dedicated time & $\begin{array}{l}\text { Dedicate more time } \\
\text { to the peer review } \\
\text { process. }\end{array}$ & $\begin{array}{l}\text { "Have time blocked out for residents so we can review our } \\
\text { own patients and note the changes we have made." (Resident } \\
\text { 7) }\end{array}$ \\
\hline & $\begin{array}{l}\text { Data-informed } \\
\text { management }\end{array}$ & $\begin{array}{l}\text { Provide residents with } \\
\text { data on their chronic } \\
\text { pain patients. }\end{array}$ & $\begin{array}{l}\text { "If we were given...data on our [chronic pain] patients...that } \\
\text { would help us have something tangible to go off of from a } \\
\text { population standpoint." (Resident } 4 \text { ) }\end{array}$ \\
\hline
\end{tabular}

applied to other guided interventions to improve patient care.

\section{Discussion}

This residency-wide intervention combining didactic guided instruction and interdisciplinary peer-topeer discussion had a positive impact on opioid prescribing practice for reviewed patients, particularly when PCPs were able to successfully implement recommendations. Residents who participated in qualitative interviews unanimously had a positive impression of the opioid peer review process, citing that the systematic approach helped to heighten their awareness of best practices for opioid prescribing. Next steps for the study could include screening patients for opioid use disorder and offering appropriate treatment, as well as utilizing additional resources 
or role-playing to simulate challenging patient discussions. ${ }^{14}$

Limitations of our study include a small sample size and evaluation of the intervention within a single residency program. Additionally, since the MME was taken as a snapshot of 1-month postintervention and at 6 months, long-term patient outcomes are not known. The size of the educational intervention did not permit evaluation of patient-oriented outcomes, such as premature death.

In conclusion, an interdisciplinary, guided peer-review intervention proved to be an asset in resident instruction and implementation of CDC opioid guidelines.

\section{*Footnote}

High average monthly MME defined as $\geq 50 \mathrm{MME} /$ day for $\geq 90$ days and/or patients prescribed opioids and benzodiazepines concurrently.

FINANCIAL SUPPORT: Financial support was provided by the Department of Family Medicine of Michigan State University College of Human Medicine.

PRESENTATIONS: This study was presented at the 48th North American Primary Care Research Group Annual Meeting (Virtual), November 23, 2020; and

2021 Society of Teachers of Family Medicine Annual Spring Conference, May 3-5, 2021 (virtual).
CORRESPONDING AUTHOR: Address correspondence to Dr Leora Aquino, NYU Langone Brooklyn, 150 55th Street, Brooklyn, NY 11220. 718-630-7000. leoratricia.aquino@nyulangone.org.

\section{References}

1. What Is the US Opioid Epidemic? US Department of Health and Human Services. 2021. Accessed December 2, 2021. https://www.hhs. gov/opioids/about-the-epidemic/index.htm

2. Weiner S. COVID-19 and the opioid crisis: When a pandemic and an epidemic collide. Association of American Medical Colleges. July 2020. Accessed July 27, 2020. https://www. aamc.org/news-insights/covid-19-and-opioidcrisis-when-pandemic-and-epidemic-collide

3. Wan W, Long H. 'Cries for help': Drug overdoses are soaring during the coronavirus pandemic. The Washington Post. July 1, 2020. Accessed December 1, 2021. https://www.washingtonpost.com/health/2020/07/01/coronavirusdrug-overdose/

4. Zoberi K, Everard KM. Teaching chronic pain in the family medicine residency. Fam Med. 2018;50(1):22-27. doi:10.22454/ FamMed.2018.134727

5. Khalid L, Liebschutz JM, Xuan Z, et al. Adherence to prescription opioid monitoring guidelines among residents and attending physicians in the primary care setting. Pain Med. 2015;16(3):480-487. doi:10.1111/pme.12602

6. Thibodeaux AM, Foster KC, Skelley JW, Sim M. Opioid prescribing habits in a family medicine residency program for the management of non-cancer pain. Innov Pharm. 2019;10(2):10. doi:10.24926/iip.v10i2.1149

7. Austin RC, Fusco CW, Fagan EB, et al. Teaching opioid tapering through guided instruction. Fam Med. 2019;51(5):434-437. doi:10.22454/ FamMed.2019.502509
8. Coon SA, Hill LG, Hutchison RW, et al. Mobilizing pharmacists to address the opioid crisis: A joint opinion of the ambulatory care and adult medicine practice and research networks of the American College of Clinical Pharmacy. J Am Coll Clin Pharm. 2020;3:1493-1513. doi:10.1002/jac5.1331

9. Fujita AW, LaRosa A, Carter A. Treating withdrawal and pain in inpatients with opioid use disorder: a brief educational intervention for internal medicine residents. MedEdPORTAL. 2021;17:11123. doi:10.15766/mep_23748265.11123

10. Lagisetty, P., Klasa, K., Bush, C., Heisler, M., Chopra, V., \& Bohnert, A. (2017). Primary care models for treating opioid use disorders: What actually works? A systematic review. In PLoS ONE (Vol. 12, Issue 10). doi:10.1371/journal. pone. 0186315

11. Arizmendez NP, Kotovicz F, Kram JJF, Baumgardner DJ. Multimodal local opioid prescribing intervention outcomes in chronic noncancer pain management. J Am Board Fam Med. 2019;32(4):559-566. doi:10.3122/ jabfm.2019.04.180296

12. Calculating Total Daily Dose of Opioids for Safer Dosage. Centers for Disease Control and Prevention. Published 2008. Accessed September 10, 2020 https://www.cdc.gov/drugoverdose/ pdf/calculating_total_daily_dose-a.pdf

13. Hsieh HF, Shannon SE. Three approaches to qualitative content analysis. Qual Health Res. 2005;15(9):1277-1288. doi:10.1177/1049732305276687

14. Scope of Pain, Safer/Competent Opioid Prescribing Education Micro-cases. Boston University School of Medicine. Published 2021. Accessed September 22, 2021. https://www. scopeofpain.org/micro-cases/ 